Int. J. Dev. Biol. 56: 877-887 (2012)

doi: $10.1387 / \mathrm{ijdb} .120149 \mathrm{ab}$

\title{
Genome organization and epigenetic marks in mouse germinal vesicle oocytes
}

\author{
AMELIE BONNET-GARNIER* ${ }^{* 1,2}$, PRISCA FEUERSTEIN ${ }^{1,2}$, MARTINE CHEBROUT ${ }^{1,2}$, RENAUD FLEUROT ${ }^{1,2}$, \\ HABIB-ULLAH JAN ${ }^{1,2, \#, ~ P A S C A L E ~ D E B E Y ~}{ }^{1,2}$ and NATHALIE BEAUJEAN ${ }^{1,2}$ \\ ${ }^{1}$ INRA, UMR1198 Biologie du Développement et Reproduction, Jouy-en-Josas and ${ }^{2}$ ENVA, Maisons Alfort, France
}

\begin{abstract}
During the final step of oogenesis, the oocyte nucleus is subject to large-scale modifications that correlate with transcriptional silencing. While oocytes with dense chromatin around the nucleolus are silent (SN, surrounded nucleolus), oocytes with uncondensed chromatin (NSN, non-surrounded nucleolus) are transcriptionally active. It is believed that epigenetic mechanisms that participate in gene expression regulation could play a role in this event. In this context, we examined the behaviour of heterochromatin and related histone modifications during the NSN to SN transition by immunostaining. Using fluorescent in situ hybridization on three dimensionalpreserved nuclei (3D-FISH), we also studied the distribution of centromeric, pericentromeric and ribosomal (rDNA) sequences in relation to the nucleolus (also called the nucleolus-like body, NLB). We observed that in NSN-type oocytes, pericentromeric heterochromatin is aggregated within chromocenters. In SN-type oocytes, pericentromeric heterochromatin and centromeres form a discontinuous ring around the NLB. rDNA sequences, which initially present a pearl necklace structure, gather together in seven highly condensed foci at the NLB periphery. H3K9me3 and H4K20me3 heterochromatin marks clearly label chromocenters, whereas H3K4me3 and H4K5ac are totally excluded from heterochromatin regions, even in the very compact SN-nuclei. Remarkably, H3K27me3 displays an intermediate behavior. It appears that GV oocyte nuclei exhibit a specific epigenetic landscape. Histone modifications, related to both active and repressive chromatin structures, seem to follow the large-scale chromatin movements that occur during the NSN to SN transition. We also demonstrate that, while heterochromatin regions re-localize around the NLB, rDNA sequences adopt a highly compact structure in SN-type oocytes.
\end{abstract}

KEY WORDS: oocyte, mouse, epigenetic, rDNA, chromocenter

\section{Introduction}

In mouse, the pre-antral oocyte arrested in prophase l of meiosis (also called germinal vesicle or GV oocyte) is a unique model that offers the opportunity to study large-scale chromatin modifications in relation with gene expression changes (see review of De La Fuente, 2006). During this final step of oogenesis, the oocyte nucleus is subject to important nuclear architecture modifications (Debey et al., 1993; Zuccotti et al., 1995). Indeed, two main types of nuclear organization in GV oocytes have been described: the SN-type (Surrounded Nucleolus) and the NSN-type (Non Surrounded Nucleolus). It should be mentioned here that in fully grown GV oocytes the 'nucleolus' as an unusual ultrastructure and function, it is therefore often referred to as 'nucleolus like body' or NLB (Bouniol-Baly et al., 1999; Kopecny et al., 1995). In SN-oocytes, the chromatin is compacted and forms a ring around this NLB whereas in the NSN ones the chromatin is not condensed around the NLB (Debey et al.,

Abbreviations used in this paper: 3D-FISH, fluorescent in situ hybridization on three dimension preserved nuclei; BSA, bovine serum albumin; CENPs, centromeric proteins A/B; dbcAMP, dibutyryl cyclic adenosine mono-phosphate; FISH, fluorescent in situ hybridization; FITC, fluorescein isothiocyanate; GV, germinal vesicle; H3K27me3, histone 3 tri-methylated in lysine 27; $\mathrm{H} 3 \mathrm{~K} 4 \mathrm{me} 3$, histone 3 tri-methylated in lysine 4; H3K9me3, histone 3 tri-methylated in lysine 9; H4K20me3, histone 4 tri-methylated in lysine 20; $\mathrm{H} 4 \mathrm{~K} 5 \mathrm{Ac}$, histone 4 acetylated in lysine 5; HP1, heterochromatin protein 1; Int, intermediate; Mll 2, mixed-lineage leukemia 2; NLB, nucleolus-like body; NOR, nucleolar organizer regions; NSN, non-surrounded nucleolus; PBS, phosphate-buffered saline; PFA, paraformaldehyde; rDNA, ribosomal DNA or ribosomal RNA genes; RPA1 16, 116-kDa subunit of RNA polymerase I; RPA53, 53-kDa subunit of RNA polymerase I; RT, room temperature; SN, surrounded nucleolus; SSC, saline sodium citrate; UBF, upstream binding factor.

*Address correspondence to: Amélie Bonnet-Garnier. INRA, UMR1198 Biologie du Développement et Reproduction, F-78350 Jouy-en-Josas, France.

Tel: +33-1-34-65-2379. Fax: +33-1-34-65-2909; e-mail: amelie.bonnet-garnier@jouy.inra.fr; http://www.jouy.inra.fr/bdr

\# Present address: Department of Animal Breeding \& Genetics, KPK Agricultural University Peshawar, Pakistan.

Final, author-corrected PDF published online: 5 February 2013.

ISSN: Online 1696-3547, Print 0214-6282

(C) 2013 UBC Press

Printed in Spain 

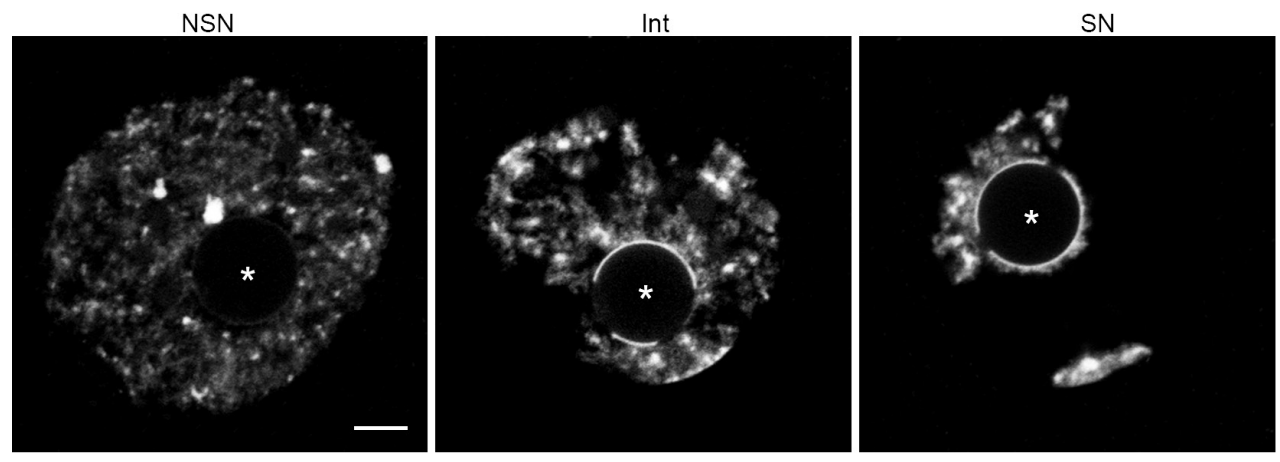

Fig. 1. Examples of the three types of chromatin configurations in germinal vesicle (GV) mouse oocytes. Representative images shown here are confocal single z-sections of DNA stainings with Yopro I. The NSN-type oocytes (Non Surrounded Nucleolus) show a decondensed chromatin configuration and the SN-type oocytes (Surrounded Nucleolus) a highly condensed chromatin with a ring around the NLB (Nucleolus Like Body). The Intermediate (Int) oocytes show a less condensed chromatin and a partial ring of chromatin around the NLB. The position of the NLB is indicated by $(*)$. Scale bars: $5 \mu \mathrm{m}$.

1993; Mattson and Albertini, 1990; Parfenov et al., 1989; Zuccotti et al., 1995). These chromatin configuration changes have been correlated with differential transcriptional activity (Bouniol-Baly etal., 1999; Christians et al., 1999; Miyara et al., 2003). SN types oocytes are silent while NSN-type oocytes are transcriptionally active and synthesize all classes of RNA (Bouniol-Baly et al., 1999; De La Fuente and Eppig, 2001; Kaplan et al., 1982; Liu and Aoki, 2002). Although these two types of oocyte are able to resume meiosis, they do not have the same developmental competence (Inoue et al., 2008; Zuccotti et al., 1998; Zuccotti et al., 2008; Zuccotti et al., 2002). Following fertilization, NSN-derived embryos stop to develop at the two-cell stage while $\mathrm{SN}$-derived embryos pursue development until the blastocyst stage and to term (Inoue et al., 2008; Zuccotti et al., 1998; Zuccotti et al., 2002).

Among the various epigenetic mechanisms known to participate in the regulation of genes expression are histone modifications (mainly acetylation and methylation) and higher-order chromatin organization (Kouzarides, 2007; Zhou et al., 2011). These epigenetics mechanisms can contribute to fine-tuning of gene expression levels: from active to poised to inactive (Zhou et al., 2011) and may be of importance in the context of the oocyte nucleus that becomes totally silent.

In the past decade, several groups already analyzed histone modifications in fully-grown mouse oocytes. Whereas an intense staining for all acetylated lysine residues at histone $\mathrm{H} 4$ (K5; K8, K12 and $\mathrm{K} 16)$ or $\mathrm{H3}$ (K9, K14 and K18) can be observed in GV oocytes (De La Fuente et al., 2004; Kim et al., 2003; Sarmento et al., 2004; Spinaci et al., 2004), it disappears upon germinal vesicle breakdown and in metaphase II oocytes (Kim et al., 2003). Methylated histones have also been studied although no comparison between

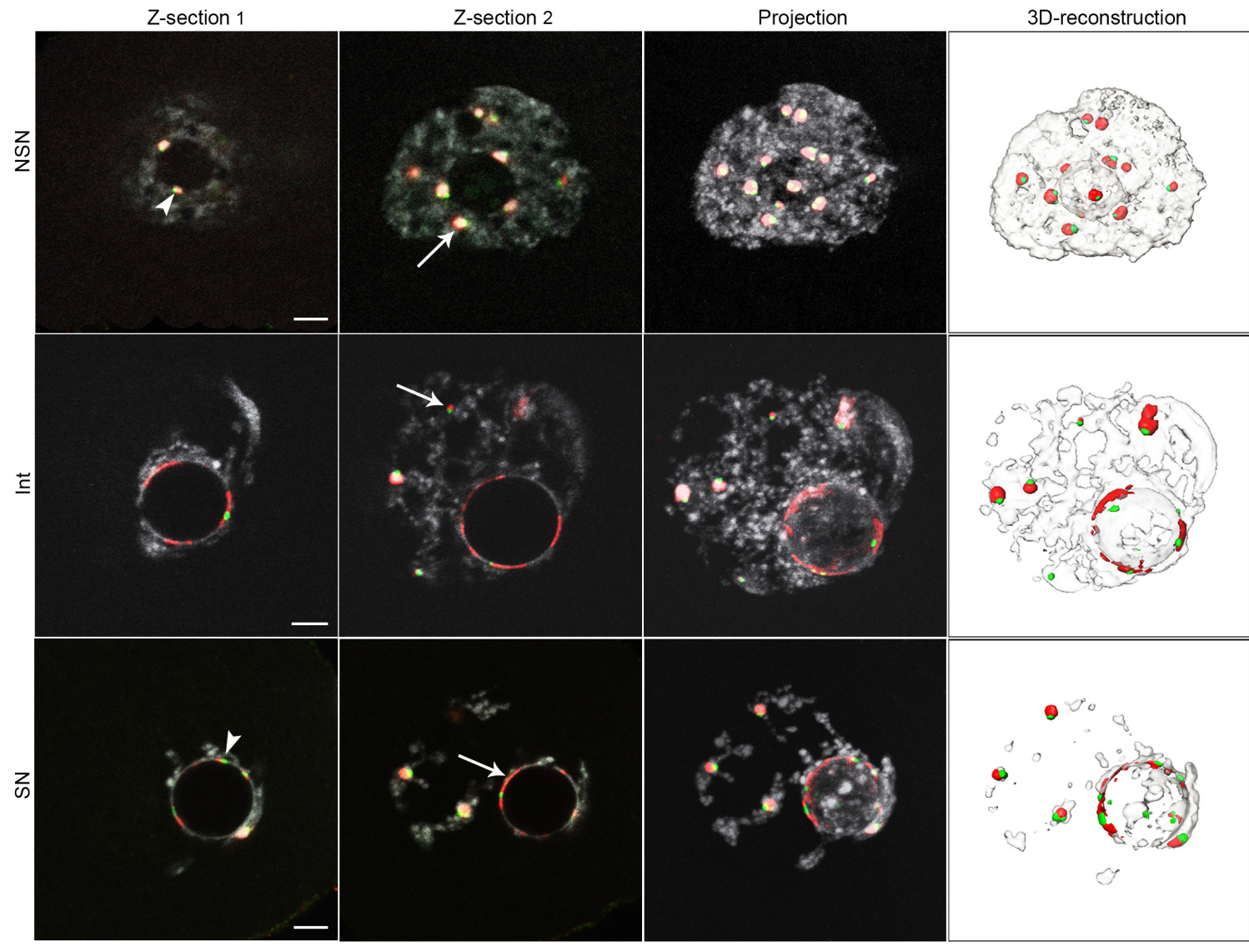

Fig. 2. Distribution of the pericentromeric and centromeric FISH signals in germinal vesicle (GV) oocytes. Oocytes were stained by FISH with major satellites (red) and minor satellites (green) probes; DNA was counterstained with propidium iodide (grey). Two different single confocal sections ( $z$ section 1 and 2) are shown here for each type of GV oocytes (NSN, Int and SN), as well as the corresponding Z-stack projections and the $3 D$ reconstructions. Arrows indicate the different major satellites signals we distinguished in our image analysis: (i) chromocenters (NSN, z-section 2), (ii) small aggregates (Int, z-section 2) and (iii) partial rims (SN, z-section 2). Arrowheads indicate minor satellites spots localized next to a chromocenter (NSN, Zsection 1) or around the $N L B(S N, z$-section 1). Scale bars: $5 \mu \mathrm{m}$. 
NSN to SN-type oocytes was done (Liu et al., 2004; Sarmento et al., 2004). In 2007, Kageyama and coworkers quantified the levels of several epigenetic marks such as histone acetylation (H3K9/K18 and H4K5/K12) and histone methylation (H3K4 /K9 di and tri-methylated) during GV oocytes final maturation. They concluded that SN-type oocytes show relatively higher levels of epigenetic modifications when compared to NSN-type ones. These data suggest that epigenetic histone modifications evolve during oocyte maturation and that there might be a link with the oocyte transcriptional status.

Most studies mentioned above provide general information about the presence and the levels of histone modifications in GV oocytes, but very few refer to their nuclear distribution and to the possible relationship with higher-order chromatin organization. Epigenetic modifications are indeed thought to modulate higher-order chromatin structure at the nuclear level and thereby regulate gene expression (Schneider and Grosschedl, 2007). Many examples in the literature have shown such nuclear reorganization upon differentiation as well as a direct link between genes position and expression (Francastel et al., 2000; Gilbert et al., 2004; Tessadori et al., 2007; Zink et al., 2004). Remarkably, pericentromeric heterochromatin is a constitutive higher-order chromatin structure that plays a role not only in chromosome segregation but also in transcriptional silencing (Choo, 2000; Francastel et al., 1999). In interphasic somatic cells, these regions are usually forming chromocenters that represent clusters of the pericentric regions of different chromosomes, surrounded by the centromeres of the corresponding chromosomes (Bannister et al., 2001; Lachner et al., 2001). In GV oocytes, it has already been demonstrated that HP1 ( $\alpha$ or $\beta$ ) proteins - known to be associated with pericentromeric heterochromatin (Bannister et al., 2001; Lachner et al., 2001)- co-localize with highly condensed areas of chromatin in the nucleoplasm of NSN and SN oocytes as well as around the NLB of SN oocytes (Chang et al., 2005; Liu et al., 2012; Meglicki et al., 2008; Wang et al., 2008). It was also shown that centromeres cluster around the NLB in SN oocytes only (De La Fuente et al., 2004; Garagna et al., 2004; Liu et al., 2012; Longo et al., 2003; Zuccotti et al., 2005), suggesting that pericentromeric heterochromatin distribution is reorganized during the NSN to SN transition. Only two studies (Liu et al., 2012; Meglicki et al., 2008) analyzed epigenetics marks related to heterochromatin regions (centromeric and/or pericentromeric) in NSN- and SN-oocytes. They have found that the so-called "repressive" H3K9me3 and H3K27me3 marks indeed localize with dense heterochromatin regions, like in somatic cells (Peters et al., 2003), whereas the "permissive" H3Ac mark labeled only the decondensed euchromatin regions.

Altogether it appears that epigenetic modifications might play an important role in the NSN to SN transition, but their relationship with higher-order chromatin reorganization taking place during this transition is still poorly understood. To get a deeper insight into the characterization of heterochromatin organization during the NSN to SN transition, we examined the behaviour of centromeric and pericentromeric regions by immuno-staining approaches, using specific related proteins and their corresponding histone modifications, as well as 3D-FISH (Fluorescent In situ Hybridization) with specific probes, on oocytes with 3D-preserved nuclei. We also studied the distribution of ribosomal RNA genes (rDNA) that are associated to the nucleolus. Zatsepina and coworkers
(2000) indeed described changes in the distribution of the rDNA transcription machinery when the nucleolus becomes inactive. Similarly, Longo and coworkers (2003) observed that NOR (Nucleolar Organizer Region) staining changes when oocytes acquire the SN nuclear organisation. Therefore, the relationship between these ribosomal regions and the pericentromeric ones that also surround the NLB had to be examined.

\section{Results}

As previously reported, large-scale chromatin reorganization occurs during the time course of oogenesis (De La Fuente, 2006; Debey et al., 1993; Longo et al., 2003; Zuccotti et al., 1995). In juvenile mouse females, the oocyte nucleus is initially in the NSN configuration during the first weeks after birth (from 100\% to $91 \%$ at 12 to 17 days after birth, Table 1 and Bouniol-Baly et al., 1999; Zuccotti et al., 2005). Then, with female aging, other types of configuration appear. When females reach full sexual maturity (6 to 8-week-old), three types of configuration can be distinguished (Table1): SN type (about 39\% of the oocytes); Intermediate type (about 20\%) and NSN type (about 37\%). In the NSN-type oocytes, euchromatin shows a decondensed configuration since heterochromatin aggregates to form clusters called chromocenters (Fig. 1 and Zuccotti et al., 2005). In SN-type oocytes, chromatin is highly condensed and forms a ring around the NLB (nucleolus like body) while in Intermediate (Int) oocytes

TABLE 1

\section{DISTRIBUTION OF THE THREE TYPES OF CHROMATIN CONFIGURATION IN OOCYTE NUCLEI DEPENDING ON FEMALE MOUSE AGE}

\begin{tabular}{lcccccc} 
Mouse age & 12 days & $\mathbf{1 5}$ days & $\mathbf{1 7}$ days & $\mathbf{2 1}$ days & $\mathbf{6}$ weeks & $\mathbf{8}$ weeks \\
\hline $\mathrm{N}^{\circ}$ of NSN-type oocytes & 37 & 14 & 28 & 4 & 18 & 28 \\
& $(100 \%)$ & $(100 \%)$ & $(91 \%)$ & $(33 \%)$ & $(43 \%)$ & $(37 \%)$ \\
$\mathrm{N}^{\circ}$ of Int-type oocytes & 0 & 0 & 3 & 7 & 11 & 15 \\
& & & $(9 \%)$ & $(58 \%)$ & $(26 \%)$ & $(20 \%)$ \\
$\mathrm{N}^{\circ}$ of SN-type oocytes & 0 & 0 & 0 & 1 & 11 & 29 \\
& & & & $(8 \%)$ & $(26 \%)$ & $(39 \%)$ \\
$\begin{array}{l}\text { Total number of oocytes } \\
\text { analyzed }\end{array}$ & 37 & 14 & 31 & 12 & 42 & 75 \\
\hline
\end{tabular}

TABLE 2

\section{DISTRIBUTION OF THE CENTROMERIC REGIONS ANALYZED EITHER BY FISH OR IMMUNO-DETECTION IN EACH TYPE OF OOCYTE}

\begin{tabular}{|c|c|c|c|c|}
\hline & & NSN & Int & SN \\
\hline \multirow{4}{*}{ 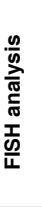 } & Number of oocytes analyzed & 25 & 6 & 25 \\
\hline & $\begin{array}{l}\text { Total number of minor satellite spots } \\
\text { detected }\end{array}$ & $\begin{array}{c}16.0 \pm 2.2 \\
{[12-20]}\end{array}$ & $\begin{array}{c}15.5 \pm 2.6 \\
{[12-29]}\end{array}$ & $\begin{array}{c}16.4 \pm 1.5 \\
{[14-19]}\end{array}$ \\
\hline & $\begin{array}{l}\mathrm{N}^{\circ} \text { of minor spots associated to major } \\
\text { ones within chromocenters }\end{array}$ & $\begin{array}{c}16.0 \pm 2.3 \\
{[12-20]}\end{array}$ & $\begin{array}{c}10.0 \pm 3.2 \\
{[6-15]}\end{array}$ & $\begin{array}{c}7.0 \pm 1.9 \\
{[4-10]}\end{array}$ \\
\hline & $\mathrm{N}^{\circ}$ of minor spots associated to NLBs & $0 \pm 0$ & $\begin{array}{l}5.5 \pm 2.8 \\
{[0-8]}\end{array}$ & $\begin{array}{c}9.2 \pm 2.3 \\
{[5-13]}\end{array}$ \\
\hline \multirow{4}{*}{ 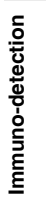 } & Number of oocytes analyzed & 46 & 26 & 41 \\
\hline & Total number of CENP spots & $\begin{array}{l}10.0 \pm 4.2 \\
{[2-19]}\end{array}$ & $\begin{array}{c}11.8 \pm 3.0 \\
{[3-18]}\end{array}$ & $\begin{array}{l}11.8 \pm 2.5 \\
{[8-20]}\end{array}$ \\
\hline & $\begin{array}{l}N^{\circ} \text { of CENP spots located in the } \\
\text { nucleoplasm }\end{array}$ & $\begin{array}{c}10.0 \pm 4.2 \\
{[2-19]}\end{array}$ & $\begin{array}{c}7.8 \pm 2.8 \\
{[3-14]}\end{array}$ & $\begin{array}{c}7.0 \pm 2.1 \\
{[1-12]}\end{array}$ \\
\hline & $\mathrm{N}^{\circ}$ of CENP spots associated to NLB & $0 \pm 0$ & $\begin{array}{c}4.3 \pm 2.2 \\
{[1-10]}\end{array}$ & $\begin{array}{c}4.8 \pm 2.0 \\
{[1-9]}\end{array}$ \\
\hline
\end{tabular}
indicated next. 
a mixed configuration in-between NSN and SN is observed with decondensed chromatin in the nucleoplasm and only a partial ring of chromatin around the NLB (Fig. 1).

\section{What do we know about heterochromatin organization in germinal vesicle oocytes?}

In order to get a deeper insight into the status of chromatin in GV oocytes, we have examined the localization of centromeric and pericentromeric heterochromatin in these oocytes using two different approaches: 1) immuno-fluorescent detection with antibodies against HP1 $\beta$ (Heterochromatin Protein 1, associated to pericentromeric heterochromatin) and CENPs (centromeric proteins $\mathrm{A} / \mathrm{B}$, targeted by CREST serum); 2) Fluorescent in situ Hybridization (FISH) with DNA probes corresponding to either the major satellite sequences (a 234bp length motif, specific to the pericentromeric chromosome regions) or to the minor satellite sequences (a $120 \mathrm{bp}$ motif specific to the centromeric regions, Choo, 1997).

As shown in Fig. 2, in NSN-type oocytes, we observed small centromeric spots (both with the minor satellite probes and the CREST serum) associated with pericentromeric DNA (labelled by major satellite probes or HP1 $\beta$ antibody) within the so-called chromocenters (Fig. 2, arrow and arrow head in the NSN-type oocyte and Fig. 3). These chromocenters generally have more
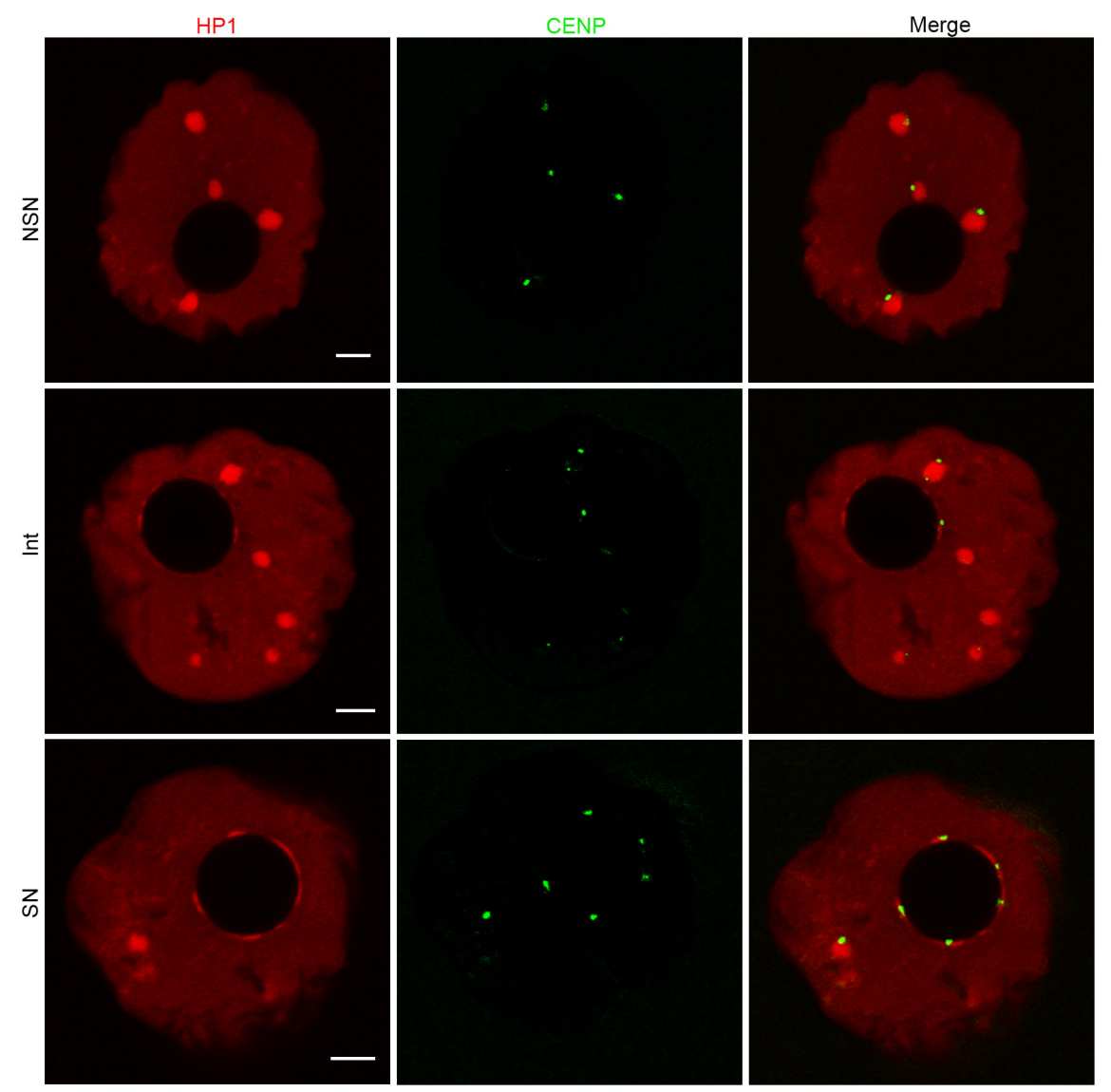

Fig. 3. Immunofluorescent detection of HP1 $\beta$ and CENP proteins in germinal vesicle oocytes. Single confocal z-sections show pericentromeric (HP1 $\beta$, red) or centromeric (CENP, green) regions for NSN, Int and SN type oocytes. The last column corresponds to merge images with both signals. Scale bars: $5 \mu \mathrm{m}$.
TABLE 3

\section{DISTRIBUTION OF THE PERICENTROMERIC REGIONS ANALYZED EITHER BY FISH OR IMMUNO-DETECTION IN EACH TYPE OF OOCYTE}

\begin{tabular}{|c|c|c|c|c|}
\hline & & NSN & Int & SN \\
\hline \multirow{5}{*}{ 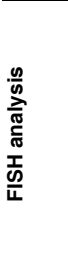 } & Number of oocytes analyzed & 44 & 9 & 44 \\
\hline & $\begin{array}{l}\text { Total number of major satellite foci } \\
\text { detected }\end{array}$ & $\begin{array}{l}11.1 \pm 2.3 \\
{[7-17]}\end{array}$ & $\begin{array}{l}13.3 \pm 4.0 \\
{[7-18]}\end{array}$ & $\begin{array}{l}16 \pm 2.2 \\
{[10-20]}\end{array}$ \\
\hline & $\begin{array}{l}\mathrm{N}^{\circ} \text { of major satellite foci associated to } \\
\text { minor spots within chromocenters }\end{array}$ & $\begin{array}{c}8.2 \pm 1.9 \\
{[7-14]}\end{array}$ & $\begin{array}{c}4.6 \pm 1.3 \\
{[3-6]}\end{array}$ & $\begin{array}{c}4.5 \pm 1.5 \\
{[1-8]}\end{array}$ \\
\hline & $\begin{array}{l}\mathrm{N}^{\circ} \text { of major satellite foci located } \\
\text { around the NLBs }\end{array}$ & $\begin{array}{l}5.7 \pm 2.3[ \\
2-12]\end{array}$ & $\begin{array}{c}7.9 \pm 3.3 \\
{[4-12]}\end{array}$ & $\begin{array}{c}11 \pm 2.1 \\
{[6-15]}\end{array}$ \\
\hline & $\mathrm{N}^{\circ}$ of small major satellite FISH signals & $\begin{array}{c}3.6 \pm 2.0 \\
{[0-8]}\end{array}$ & $\begin{array}{c}2.6 \pm 2.6 \\
{[1-8]}\end{array}$ & $\begin{array}{l}1.0 \pm 0.9 \\
2.0[0-4]\end{array}$ \\
\hline \multirow[b]{2}{*}{ 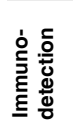 } & Number of oocytes analyzed & 46 & 26 & 41 \\
\hline & $\begin{array}{l}\mathrm{N}^{\circ} \text { of } \mathrm{HP} 1 \beta \text { foci located in the } \\
\text { nucleoplasm }\end{array}$ & $\begin{array}{c}8.8 \pm 2.2 \\
{[3-13]}\end{array}$ & $\begin{array}{c}4.6 \pm 1.9 \\
{[1-9]}\end{array}$ & $\begin{array}{c}3.6 \pm 1.4 \\
{[1-6]}\end{array}$ \\
\hline
\end{tabular}

The mean number \pm the standard deviation are indicated first, the range [minimum-maximum] is indicated next.

than two centromeric spots which confirm the association of several chromosomes in these specific structures. Interestingly, the centromeric spots were never detected around the NLB in NSN-type oocytes, neither by immuno-staining nor by $\mathrm{FISH}$ (Table 2). On the contrary, in SN-type oocytes, centromeric spots (Fig. 2, arrow head in the $\mathrm{SN}$-type oocyte) are mostly located around the NLB (these spots represent $56 \%$ of the total number of minor satellite spots detected by FISH, Table 2). Remarkably, the total number of centromeric spots was not significantly different between the three types of oocytes whatever the technique used to detect them (about 12 by immuno-staining versus 16 by FISH, Table 2). We also observed that both CENP spots and minor satellite FISH signals are less and less associated to chromocenters during the NSN to SN transition (Table 2).

The pericentromeric regions (labelled by HP1 $\beta$ antibody or major satellite probes) show more significant changes in their structure and distribution as compared to the centromeric ones (Fig. 2 and 3; Table 3). Indeed the chromocenter number decreases from about 8 in $\mathrm{NSN}$-oocytes to 4 in SN-oocytes whereas the total number of pericentromeric foci detected increases between NSN and SN oocytes (Table 3). Altogether, this suggests that pericentromeric heterochromatin gets decondense during the NSN to SN transition: 1) pericentromeric heterochromatin is initially aggregated to form the chromocenters scattered in the nucleoplasm (Fig. 2, arrow in the NSN-type oocytes; Fig. 3); 2) a more decondensed structure then appear to form a ring located around the NLB (Fig. 2, arrow in the SN-type oocyte; Fig. 3).

As expected, Intermediate-type oocytes display features of NSN and SN-type oocytes. Indeed, they have NSN-type oocyte traits such 
TABLE 4

\section{DISTRIBUTION OF TRIMETHYLATED H3K9, H3K4, H3K27, H4K20 AND ACETYLATED H4 RELATIVE TO PERICENTROMERIC OR CENTROMERIC REGIONS, OTHER CHROMATIN DOMAINS AND NLB}

\begin{tabular}{|c|c|c|c|c|c|c|c|c|c|c|c|c|}
\hline & \multicolumn{4}{|c|}{ NSN } & \multicolumn{4}{|c|}{ Int } & \multicolumn{4}{|c|}{ SN } \\
\hline & Peri & Cent & Chr & NLB & Peri & Cent & Chr & NLB & Peri & Cent & Chr & NLB \\
\hline H4K20me3 & ++ & - & - & - & ++ & - & - & $+/-$ & ++ & - & - & + \\
\hline НЗКЗme9 & ++ & - & $+/-$ & - & ++ & - & + & + & ++ & - & + & + \\
\hline H3K27me3 & - & + & + & $+/-$ & $+/-$ & + & + & $+/-$ & $+/-$ & + & + & $+/-$ \\
\hline H3K4me3 & - & - & + & + & - & - & + & - & - & - & ++ & - \\
\hline $\mathrm{H} 4 \mathrm{~K} 5 \mathrm{Ac}$ & - & - & + & - & - & - & ++ & - & - & - & ++ & - \\
\hline
\end{tabular}

Peri: pericentromeric regions; Cent: centromeric regions, Chr: rest of the chromatin and NLB: nucleolus like body.

++= strong signal, + = signal; +/- = weak signal and - = no signal

as very small major satellite or HP1 $\beta$ foci associated to one centromeric spot (arrow in Fig. 2, Table 3). On the other hand, they also have intense but discontinuous signals corresponding to $\mathrm{HP} 1 \beta /$ major satellites around the NLB as SN-type oocytes (Fig. 3).

\section{What do we know about epigenetic marks linked to active or repressive chromatin domain?}

As shown in Figs 4 and 5 (with a summary in Table 4), we then performed immuno-fluorescent detections of several histone modifications known to be associated with different genes expression profiles (Trojer and Reinberg, 2007): histone $\mathrm{H} 4$ acetylation on lysine 5 ( $\mathrm{H} 4 \mathrm{~K} 5 \mathrm{ac})$, histone $\mathrm{H} 3$ trimethylation on lysine 4 (H3K4me3), histone $\mathrm{H} 4$ trimethylation on lysine 20 (H4K20me3) and histone $\mathrm{H} 3$ trimethylation on lysine 9 or 27 (H3K9me3 and H3K27me3).

As expected for repressive epigenetic marks, we observed that $\mathrm{H} 3 \mathrm{~K} 9$ me3 was mostly co-localized with condensed chromatin regions, showing a granular labeling (Fig. 4, first column, $n=34$ NSN / 24 Int /20 SN). This signal co-localized perfectly with HP1 $\beta$ particularly within the large foci corresponding to chromocenters (Fig. 4, second column, $\mathrm{n}=18 \mathrm{NSN} / 17$ Int / $14 \mathrm{SN}$ ). Remarkably, a nearly complete ring of $\mathrm{H} 3 \mathrm{~K} 9 \mathrm{me} 3$ could be observed around the NLB in SN-type oocytes (more than with HP1 $\beta$ ). Similarly, we observed that H4K20me3, another heterochromatin associated epigenetic mark (Trojer and Reinberg, 2007), also formed a discontinuous ring around the NLB in SNtype oocytes, as H3K9me3 (Fig. 4, last column, n=9 NSN / 2 Int /8 SN). Interestingly, in NSN-type oocytes, this mark was exclusively localized on pericentromeric heterochromatin within chromocenters and excluded

Fig. 4. Immuno-fluorescent detection of HP1 $\beta$ protein and H3K9me3 / H4K20me3 epigenetic modifications in GV oocytes. Oocytes were stained with antibodies against H3K9me3, HP1 $\beta$ and H4K20me3; in some oocytes DNA was counterstained with Yopro I (green). Representative images from non-surrounded nucleolus (NSN), intermediate (Int) and surrounded nucleolus (SN) -type oocytes are shown here (confocal single z-sections). Scale bars: $5 \mu \mathrm{m}$ from centromeric regions as well as euchromatin.

Whereas H3K9me3 is known to mark constitutive heterochromatin, $\mathrm{H} 3 \mathrm{~K} 27 \mathrm{me} 3$ is usually associated to facultative heterochromatin (in contrary to constitutive heterochromatin, facultative heterochromatin can be converted back into euchromatin according to the cell type for example, Trojer and Reinberg, 2007). Remarkably, we observed a striking difference of distribution between these two marks in the three types of GV oocytes analyzed (Fig. 5, first column, $n=10$ NSN / 12 Int / 7 SN). In NSNtype oocytes, H3K27me3 small granular foci can be observed in large quantities throughout the nucleoplasm, co-localized with decondensed chromatin and excluded from the chromocenters. No specific perinucleolar labeling was observed. During the NSN to SN transition, the density of these H3K27me3 granular foci decreased dramatically and some of them became adjacent to the NLB (Fig. 5 and Table 4). No co-localization with H3K9me3 was ever observed, even in SN-type oocytes.

We next examined two permissive/active marks (Trojer and
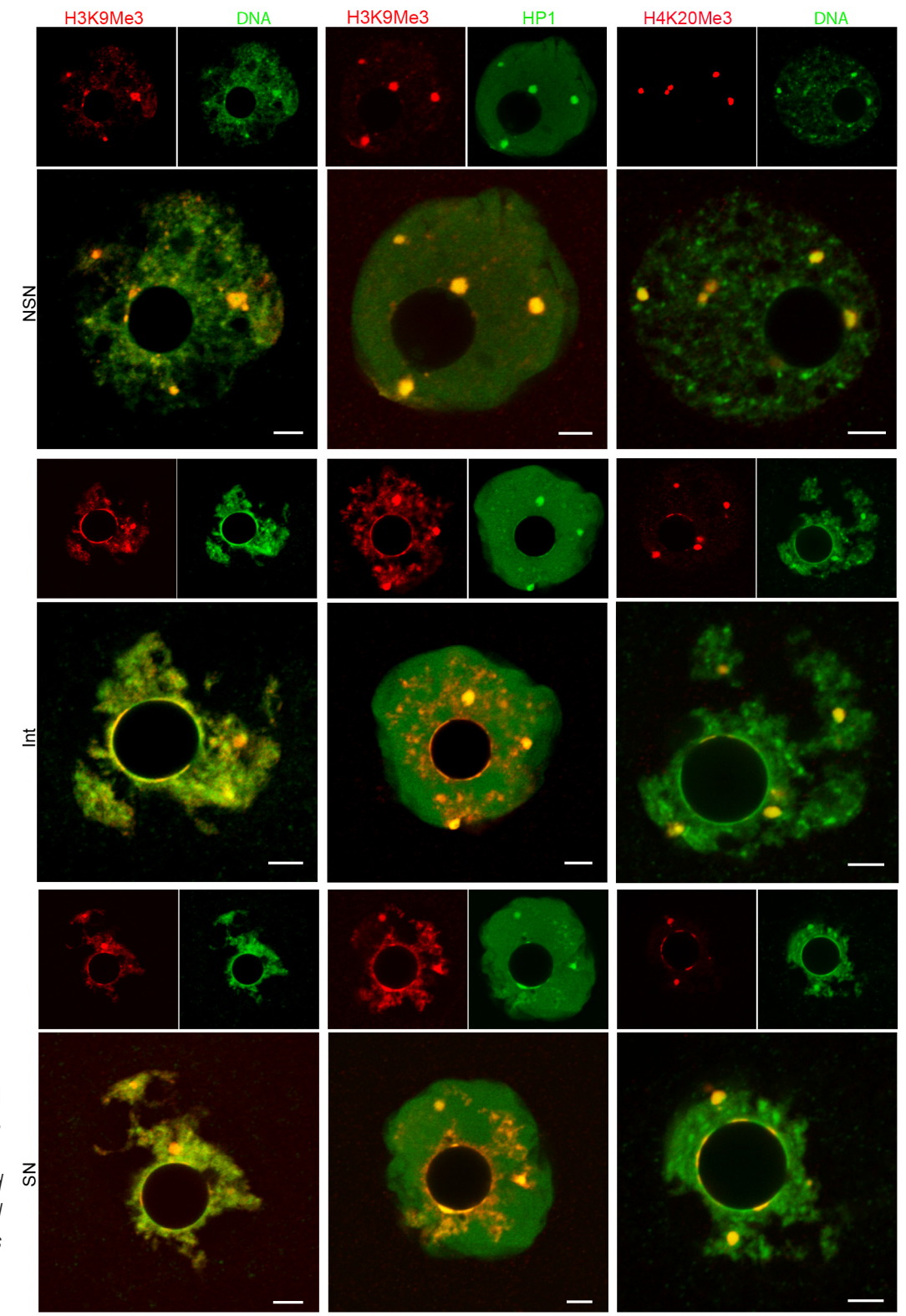


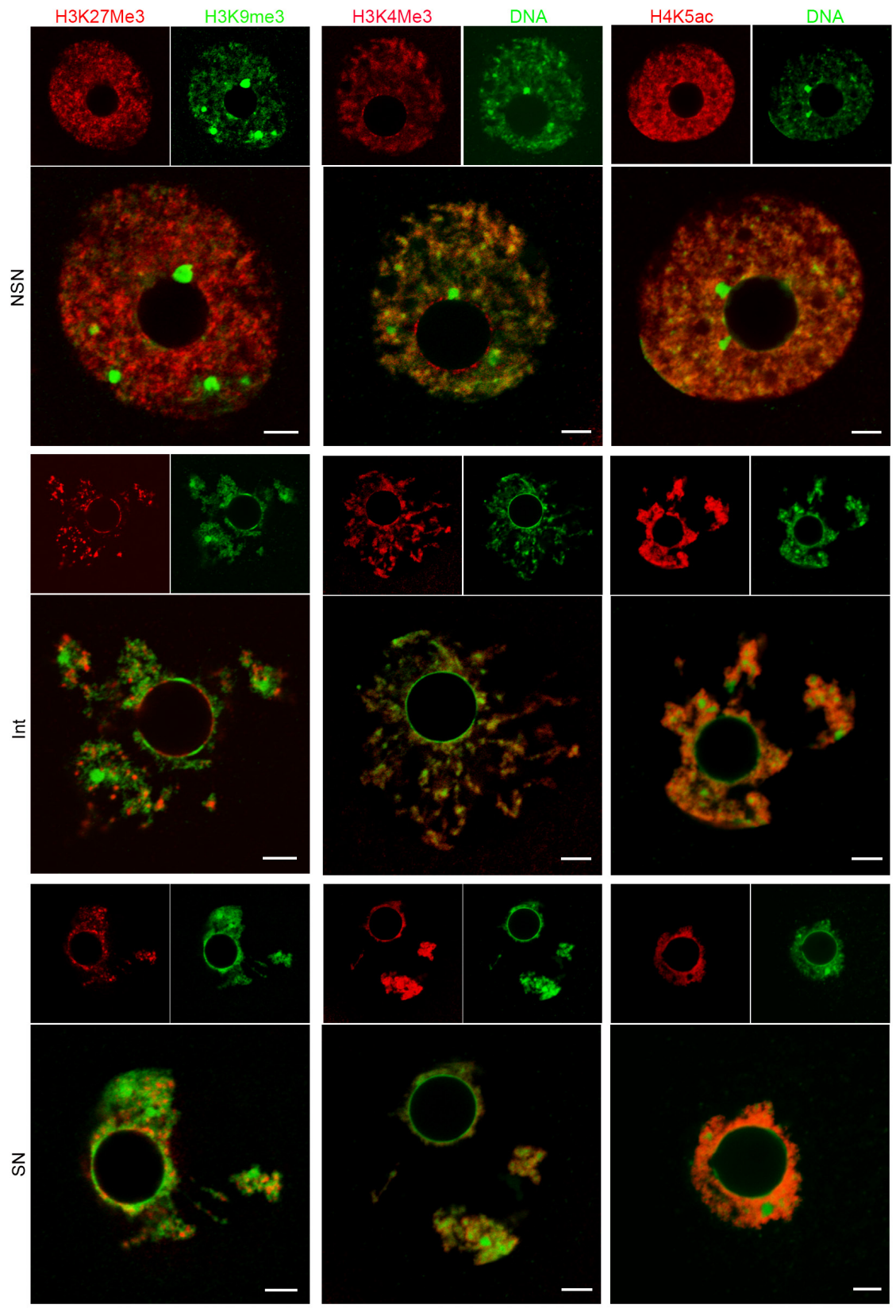

Fig. 5. Immunofluorescent detection of H3K27me3, H3K4me3 and H4K5ac epigenetic modifications in germinal vesicle oocytes. Oocytes were stained with antibodies against H3K27me3, H3K4me3 and H4K5Ac; DNA was counterstained with Yopro I (green). Representative images from NSN, Int and SN type oocytes are shown here (confocal single z-sections). Scale bars: 5 um.

Reinberg, 2007): H3K4me3 and H4K5ac. In both cases, a diffuse staining was observed throughout the nucleoplasm in NSN-type oocytes (Fig. 5, H3K4me3: $n=4$ NSN / 3 Int / 5 SN, H4K5ac: $\mathrm{n}=13 \mathrm{NSN} / 2$ Int / $8 \mathrm{SN}$ ). H3K4me3 and H4K5ac staining were co-localized with decondensed chromatin clearly excluded from DNA dense areas, i.e. from the chromocenters but also from other smaller granular heterochromatin regions. In NSN-oocytes, $\mathrm{H} 3 \mathrm{~K} 4 \mathrm{me} 3$ was also sometimes located around the NLB, looking like pearl necklaces. In Int and SN-type oocytes, this signal was not observed anymore. Finally, in SN-type oocytes, both H3K4me3 and $\mathrm{H} 4 \mathrm{~K} 5 \mathrm{ac}$ were still present and remained excluded from DNA more compact areas.

\section{What do we know about ribosomal gene orga-} nization around the nucleolus during the nonsurrounded nucleolus (NSN) to surrounded nucleolus (SN) transition?

During the NSN to SN transition, we clearly observed that pericentromeric heterochromatin accumulates around the NLB, both by FISH with major satellite probes and by immuno-stainings of the related epigenetic marks/proteins. At the same time, the NLB becomes inactive (Longo et al., 2003; Zatsepina et al., 2000). We therefore decided to examine the distribution of ribosomal sequences among fully grown oocytes using specific probes to mouse rDNA repeats (gift from J. Britton-Davidian, ISEM France), in comparison to the major satellites sequences. As described in the Material \& Methods section, the FISH protocol we used, has been modified from Koehler and coworkers (2009) in order to preserve the 3D-structure of the nuclei.

We compared the localization of rDNA FISH signals (green, Fig. 6) and major satellites ones (red, Fig. 6) in NSN $(n=20)$ and SN $(n=19)$ oocytes. We therefore counted the total number of rDNA signals (Fig. 7) and analyzed several parameters of their distribution. Actually, we identified three categories of rDNA signals: (i) those associated to NLB (Fig. 6, arrowhead in SN type oocyte z-section-1), (ii) those associated to chromocenters (Fig. 6, arrowhead in NSN-type oocyte, z-section-1) and (iii) those not associated to any major satellite signals (Fig. 6, arrowhead with $\left(^{*}\right)$ in NSN-type oocyte, z-section 2). Reversely, we also allocated the major satellites signals into two categories either associated with rDNA signals (Fig. 6, arrow in SN-type oocyte, z-section 1) or not (Fig. 6, arrow in SN-type oocyte, z-section 2). The distributions of these six different categories in NSN and SN-type oocytes are illustrated in Fig. 7 with box-plots.

All the parameters analyzed are statistically highly different between NSN and SN oocytes ( $p<0.0001$, Kruskall-Wallis test) except for the number of major satellite signals associated to rDNA sequences (7.0 \pm 1.4 in NSN and $6.9 \pm 1.5$ in SN oocytes). This last result is consistent with the NOR-bearing chromosomes number $(\mathrm{n}=7)$ described in $\mathrm{F} 1 \mathrm{C} 57 \mathrm{BI} 6 / \mathrm{JxCBA}$ mice by Romanova and coworkers (2006).

Remarkably, the total number of rDNA signals is higher in NSNtype oocytes than in SN ones (18.2 \pm 5.7 vs $10.2 \pm 2.9)$ and the rDNA sequences are less associated to major satellite sequences in NSN oocytes $(5.3 \pm 3.3$ vs $0.2 \pm 0.4)$. Together, these data may reflect a more decondensed state of these sequences in the NSN oocytes. On the opposite, in SN-type oocytes, rDNA signals became more associated to major satellite signal localized around the NLB (Fig. 6, SN-type oocyte, 3D-reconstruction) and less to chromocenter $(12.3 \pm 4.3$ vs $1.2 \pm 1.3)$. Moreover, the number of major satellites signals not associated to rDNA signals increased 

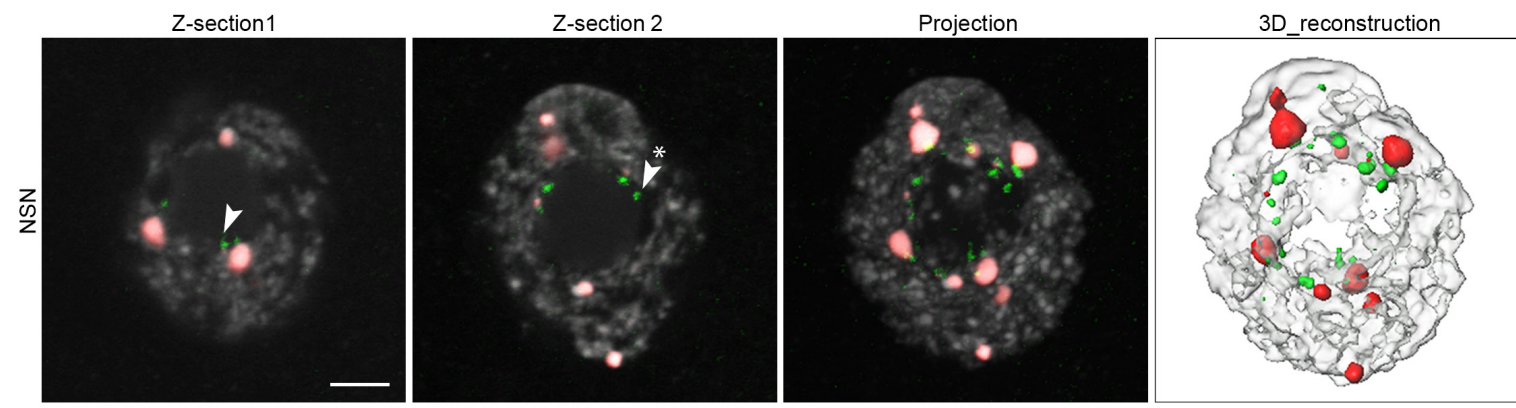

Fig. 6. Distribution of pericentromeric and rDNA sequences in germinal vesicle oocytes. Oocytes were stained
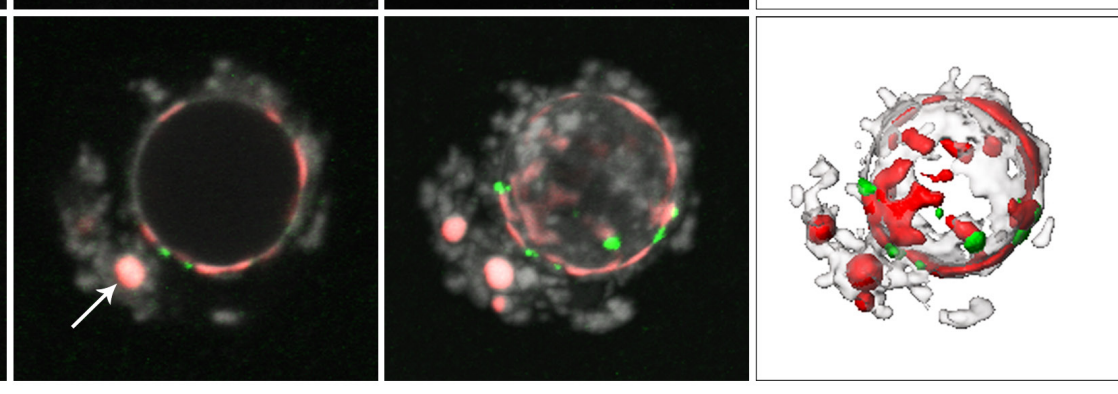
by FISH with major satellites (red) and rDNA (green) probes; DNA was counterstained with propidium iodide (grey). Two different single confocal sections (z-section 1 and 2) are shown here for each type of GV oocytes (NSN and SN), as well as the corresponding z-stack projections and the 3D reconstructions. Arrows indicate the different major satellites signals we distinguished in our image analysis: partial rims (SN, z-section 1) or chromocenters (SN, z-section 2). Arrowheads indicate rDNA sequences associated to chromocenters (NSN, z-section 1) or to the NLB (SN, z-section 1). Arrowheads with (*) indicate rDNA sequences not associated to any major satellites signal. Scale bars: 5 um.

during the NSN to $S N$ transition $(4.0 \pm 1.2$ to $7.8 \pm 3.4)$ suggesting that the pericentromeric regions (i.e. the major satellite signals) decondense to wrap the NLB while the rDNA sequences become more condensed.

\section{Discussion}

In this study we compared the nuclear distribution of constitutive heterochromatin regions (pericentric and centromeric) as well as ribosomal genes repeats (rDNA) between NSN and SN-type oocytes using 3D-FISH, a challenging technique that allows the analysis of 3D-preserved nuclei. We also examined, by immuno-staining with high resolution confocal microcopy, five histone modifications: H4K5Ac, H3K4me3, H3K27me3, H3K9me3 and H4K20me3. This approach allowed us to perform detailed analysis of NSN, Int and SN states with a particular focus on heterochromatic regions and NLB vicinity.

Three dimensional localization of constitutive heterochromatin and ribosomal sequences demonstrate large scale modification during the non-surrounded nucleolus (NSN) to surrounded nucleolus (SN) transition

To the best of our knowledge, this is the first time that constitutive heterochromatin and rDNA sequences are localized in 3D-preserved oocytes. Regarding heterochromatin localization, our observations (summarized in Fig. 8) confirm previous data obtained mostly through immunostainings (Chang et al., 2005; De La Fuente et al., 2004; Garagna et al., 2004; Longo et SN-types oocytes. al., 2003; Meglicki et al., 2008; Zuccotti et al., 2005). In NSN-type oocytes, the centromeric and pericentromeric heterochromatin are mainly organized in clusters called chromocenters-with typical posttranslational histone modifications marks- as described in somatic mouse cells (Bannister et al., 2001; Lachner et al., 2001). This result is sustained by the double immuno-staining we performed with HP1 $\beta$ and CREST antibodies. During the transition to SN-type oocytes, we observed that a more decondensed structure then appears and we assume that the pericentromeric regions expand to wrap the NLB, forming an almost complete ring. Intriguingly, the centromeric spots (detected either by FISH or immuno-staining) do not change either in size or in number (about 16 or about 12
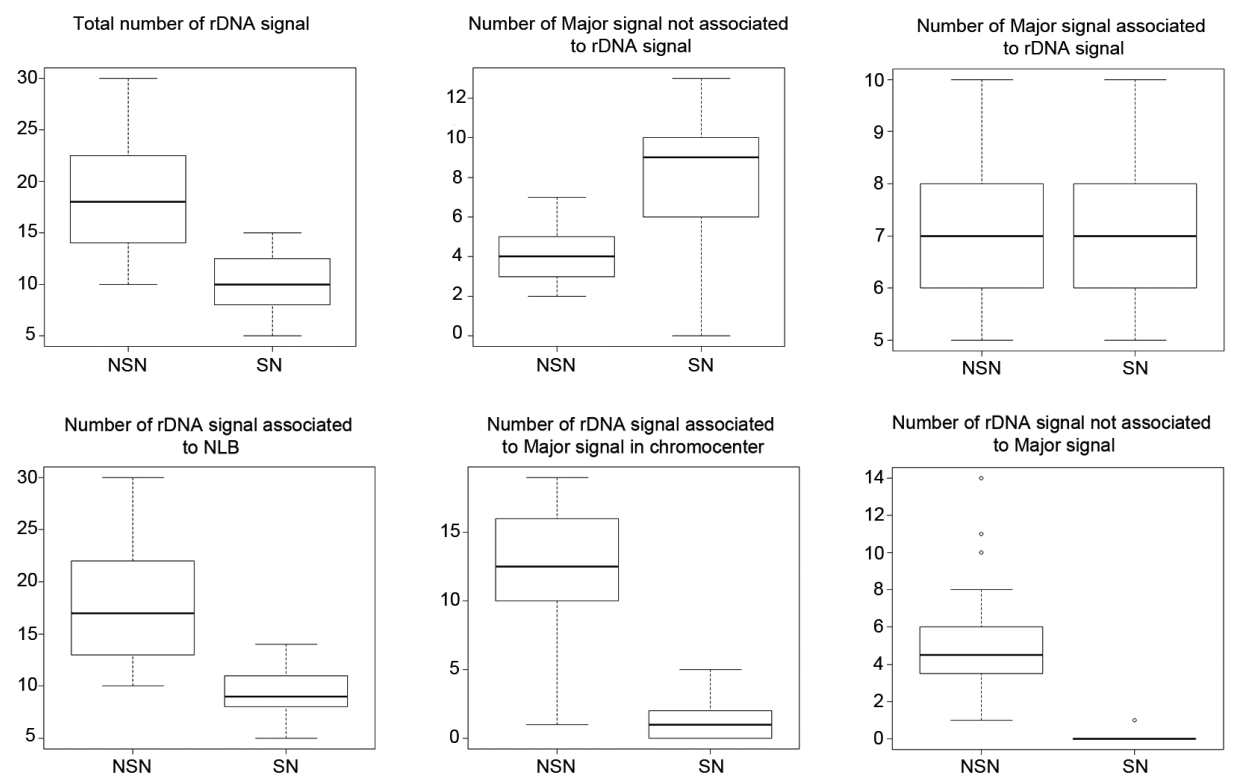

Fig. 7. Box-plot analysis of the rDNA and major satellites FISH signal distribution in NSN and 
respectively) during this transition. This is consistent with the number of centromeric spots previously reported by Garagna and coworkers (2004) in fully matured GV oocytes (about 15 detected with CREST antibodies). Therefore, despite the global chromatin compaction that occurs at the $\mathrm{SN}$ stage, pericentromeric sequences seem to decondense and centromeric sequences follow them at the periphery of the NLB.

Because we confirmed that pericentromeric heterochromatin sequences accumulate around the NLB during the NSN to SN transition, we next decided to examine the ribosomal sequences that are also localized at the NLB periphery. In NSN-type oocytes, the FISH signals corresponding to the ribosomal genes are distributed as small foci associated with the NLB surface. Intriguingly, some of them do nothave any link with the pericentromeric sequences which may reflect their highly uncondensed state. This would fit with the fact that in NSN-type oocyte the NLBs are still active (Zatsepina et al., 2000). The FISH rDNA signals are indeed organized like pearl necklaces, i.e. like the RNA polymerase I transcription complex (UBF/RPA53/RPA116) described by Zatsepina and coworkers (Zatsepina et al., 2000).

On the other hand, in SN-type oocytes, the ribosomal genes are more clustered: we do not observe pearl necklaces like signals anymore and the total number of rDNA signals is decreasing as compared to NSN oocytes (10.2 \pm 2.9 vs. $18.2 \pm 5.7$ ). We also notice that the repeated sequences condensed at the NLB surface in about seven large foci juxtaposed to major satellites FISH signals. Remarkably this corresponds to the number of rDNA foci mapped by FISH on metaphase chromosomes in somatic cells (Romanova et al., 2006). This suggests that the ribosomal regions adopt a chromosome-like structure, highly condensed, in $\mathrm{SN}$ oocytes. It should however be underlined that the number of rDNA FISH signals in SN-type oocytes we observed is higher than the number of NOR staining deposits (1 or 2) observed by Longo and coworkers (Longo et al., 2003) as well as the number of UBF/RPA53/RPA116 spots (3 to 5) described by Zatsepina and coworkers (Zatsepina et al., 2000). This suggests that only a part of the rDNA sequences are still physically associated with the RNA Polymerase I machinery components (Zatsepina et al., 2000) and we may wonder why some sequences do retain the transcription machinery proteins and some do not.

Altogether, our results demonstrate that during the NSN to SN

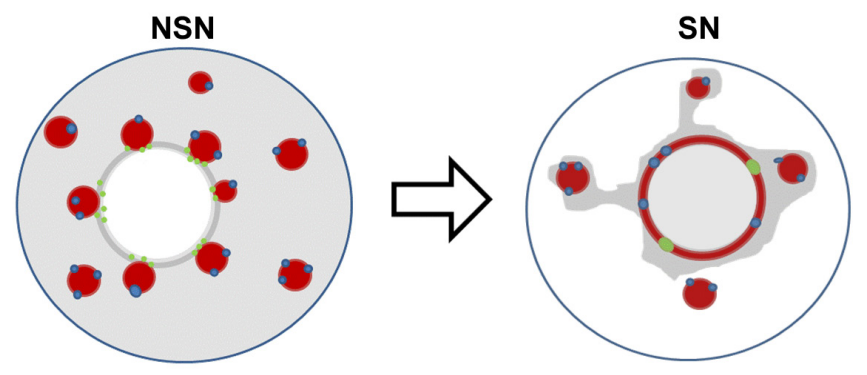

Fig. 8. Scheme illustrating the nuclear organization changes during the NSN (non-surrounded nucleolus) to SN (surrounded nucleolus) transition. Localization and shape of the centromeres (blue), pericentromeric heterochromatin (red) and ribosomal genes (green) are represented in NSN and SN type oocytes. It clearly appears that during the NSN to SN transition chromocenters number decreases to 3-4, rDNA switch from a necklace-like to a chromosome-like structure and heterochromatin extend to wrap all around the nucleolus-like body. transition heterochromatin regions envelop the NLB while the ribosomal RNA encoding genes adopt a highly compact structure. These drastic changes in the spatial genome organisation are concomitant with a global silencing of the transcription and more particularly with repression of ribosomal gene transcription that are located at the NLB surface (Zatsepina et al., 2000).

\section{Histone modifications and chromatin compaction in fully grown oocytes}

Post-translational histone modifications are known to alter chromatin configuration and thereby regulate the accessibility of transcription factors, or other regulatory proteins, to their binding sites (Zhou et al., 2011). In somatic cells specific Histone modifications have thus been correlated with different transcriptional states: active chromatin domains are for example enriched with $\mathrm{H} 4 \mathrm{~K} 5 \mathrm{ac}$ or $\mathrm{H} 3 \mathrm{~K} 4 \mathrm{me} 3$ while inactive chromatin is characterized by H3K9me3 and H4K20me3 (Schneider and Grosschedl, 2007). In this study, we examined such Histone modifications with a particular focus on their 3D-distribution within the GV oocyte nuclei.

In NSN-type oocytes, constitutive heterochromatin forming chromocenters show the same characteristic Histone modifications than in somatic cells: it is enriched in H4K2Ome3 and H3K9me3 and devoid of $\mathrm{H} 3 \mathrm{~K} 4 \mathrm{me} 3$ and $\mathrm{H} 4 \mathrm{~K} 5 \mathrm{ac}$. Our observations are in agreement with previous studies (Kageyama et al., 2007; Liu et al., 2012; Meglicki et al., 2008). We herein further demonstrate the association of $\mathrm{HP} 1 \beta$ with $\mathrm{H} 3 \mathrm{~K} 9 \mathrm{me} 3$, by co-labeling, as in somatic cells (Bannister et al., 2001). It is also the first time that H4K20me3 distribution is analyzed in details, showing a highly specific co-localization with pericentromeric heterochromatin, even more than H3K9me3.

In SN-types oocytes, most of the chromatin becomes highly compacted and aggregated around the NLB. Nevertheless H3K4me3 and $\mathrm{H} 4 \mathrm{~K} 5 \mathrm{ac}$ which are generally associated with an "open" chromatin state, are still present (De La Fuente, 2006; Liu et al., 2012, the present study). These marks are excluded from constitutive heterochromatin, as expected, but also from other smaller granular dense regions. We believe these regions might be facultative heterochromatin since similar granular foci can be observed with H3K27me3 staining in both NSN and SN-type oocytes.

Intriguingly, H3K27me3 staining was more similar to the staining of active marks ( $\mathrm{H} 3 \mathrm{~K} 4 \mathrm{me} 3$ or $\mathrm{H} 4 \mathrm{~K} 5 \mathrm{ac}$ ) than to the repressive ones (H3K9me3 or H4K20me3). Investigating further the relationship between $\mathrm{H} 3 \mathrm{~K} 4 \mathrm{me} 3$ and $\mathrm{H} 3 \mathrm{~K} 27 \mathrm{me} 3$ would be of prime interest as these two marks are known to co-localize in some genomic regions. It has indeed been suggested that these Histone modifications, called bivalent marks, can poise developmental genes until later activation or repression, during differentiation (Bernstein et al., 2006). Interestingly, oocytes lacking MLL2 -a methyltransferase responsible of H3K4 tri-methylation during oocyte growth- display a failure in global transcriptional silencing which is in opposition to its believed role of active mark (Andreu-Vieyra et al., 2010).

In somatic cells, euchromatin and heterochromatin have distinct global epigenetic marks (Trojer and Reinberg, 2007) but, altogether, our results suggest that in SN-type oocytes, common rules of the histone code are not applicable. We therefore propose that GV oocyte nuclei might have a specific histone modifications landscape. This would explain why epigenetic marks, which are attached to the nucleosomes, would follow chromatin movements during the NSN to SN transition and aggregate around the NLB without dis- 
tinction between active or repressive marks. Some authors tried to elucidate the relationship between these large scale chromatin movements and global transcriptional silencing during the NSN to SN transition. They suggest that these two events, although concomitant, are independent and that transcriptional silencing/ activity can occur without chromatin remodeling (Andreu-Vieyra et al., 2010; De La Fuente et al., 2004). However, the exact mechanisms involved remain poorly understood and further investigations are still required.

\section{Materials and Methods}

\section{Oocyte recovery}

The ovaries were collected from adult (6- to 8-week-old) C57BI6/JxCBA mice as previously described in Bouniol-Bally and coworkers (1999). Briefly, they were placed in M2 medium (Sigma Aldrich, Germany) supplemented with dibutyryl cyclic AMP (dbcAMP, $100 \mathrm{mg} / \mathrm{ml}$, Sigma Aldrich, Germany) to prevent spontaneous resumption of meiosis. GV oocyte-cumulus complexes were collected by random puncture of the ovary with a fine needle. Follicular cells surrounding the oocytes were removed mechanically by gentle pipetting through a mouth glass pipette. Oocytes were then transferred until fixation into small droplets of M2 supplemented with dbcAMP under mineral oil (Sigma Aldrich, Germany) at $37^{\circ} \mathrm{C}$.

\section{Immunofluorescent staining}

Isolated oocytes were fixed with $4 \%$ paraformaldehyde (PFA) in PBS for 10 to $20 \mathrm{~min}$, permeabilized with $0.5 \%$ Triton X-100 in PBS for 30 min, blocked in $2 \%$ BSA in PBS (1h), and processed for in toto immunofluorescent staining. All steps were performed at room temperature unless otherwise mentioned.

The following primary antibodies were used at the indicated dilutions: mouse monoclonal antibody against HP1 $\beta$ (Euromoedex \#MOD-1A9-AS, dilution 1:400), human CREST antibody which recognizes both CENP-A and B (HCT-0100, Immunovision, dilution 1:400), rabbit polyclonal antibody against H4K5Ac (Active motif, \#039584, dilution 1:300); mouse monoclonal antibody against H3K27me3 (Millipore \#07-449, dilution 1:250); rabbit polyclonal antibody against H3K9me3 (Upstate \#07-523, dilution 1:50); rabbit polyclonal antibody against $\mathrm{H} 4 \mathrm{~K} 20 \mathrm{me} 3$ (Millipore \#07-463, dilution 1:300); rabbit polyclonal antibody against H3K4me3 (Abcam \#ab8580, dilution 1:200).

Whole oocytes were incubated with the primary antibodies (diluted in $2 \%$ PBS-BSA) overnight at $4^{\circ} \mathrm{C}$; washed twice in PBS to remove any first antibody excess and then transferred in $2 \%$ BSA for $1 \mathrm{~h}$ before incubation with FITC-conjugated and Cy5-conjugated secondary antibodies from donkey against mouse or rabbit (Immuno research, Jackson laboratories, dilution 1:200) for 1 hour at RT.

\section{FISH probes and 3D FISH procedure}

Specific DNA probes for major satellites, minor satellites and ribosomal gene were amplified, purified and labelled as described below. For major satellites detection (pericentromeric heterochromatin), we used a probe prepared by PCR on genomic mouse DNA with the following primers: 5'-CATATTCCAGGTCCTTCAGTGTGC-3' and 5'-CACTTTAGGACGTGAAATATGGCG-3', and Сy3 or Cy5-labeling by random priming (Invitrogen Kit, Ref 18095-011). Similarly, for minor satellites detection (centromeric heterochromatin), we used the two following primers: 5'-ACTCATCTAATGTTCTACAGTG-3' and 5'-AAAACACATTCGTTGGAAACGCG-3'. For ribosomal genes, we use plasmids containing the cloned gene fragments of the mouse 28S rDNA (BE-2-pSP64, 1.5kb, Hassouna et al., 1984) and $18 S$ rDNA (SalC-pSP64, 2kb, Raynal et al., 1984) which were kindly provided by Pr. J. Britton-Davidian (ISEM - UMR 5554). After amplification, $28 \mathrm{~S}$ and $18 \mathrm{~S}$ rDNA were purified with PROMEGA Pure Yield Plasmid Miniprep System and labeled separately with Digoxigenin-11-dUTP by nick translation according to the Roche Protocol. Unless otherwise specified, all steps were performed at room temperature.

The 3D-FISH hybridization with major and minor satellites probes was performed on oocytes as described in Maalouf and coworkers (2009). Oocyte zona pellucida was first removed through two rapid incubations in acidic tyrode (Sigma). The oocytes were then rinsed in M2 medium, fixed in $4 \%$ paraformaldehyde (PFA) for 30 min, rinsed in PBS and gently deposited with a minimum amount of PBS on a microscope slide to allow adherence. They were then fixed again in 4\% PFA for 30 min, permeabilized for $30 \mathrm{~min}$ in $0.5 \%$ Triton X-100, and rinsed once $5 \mathrm{~min}$ in 2x saline sodium citrate (SSC) $\mathrm{pH}$ 6.3. RNA digestion was performed by incubation in $200 \mu \mathrm{g} / \mathrm{ml}$ RNase (Sigma) in $2 X S S C$ for $30 \mathrm{~min}$ at $37^{\circ} \mathrm{C}$. After two rinses 5 min each in 2XSSC, the slide was equilibrated in the hybridization buffer (50\% formamide, 2XSSC, Denhardt 1X, $40 \mathrm{mM} \mathrm{NaH} 2 \mathrm{PO} 4,10 \%$ dextran sulfate) for 1 to 2 hour(s). The probes ( $1 \mu$ l of minor and $2 \mu$ l of major satellite probes at $100 \mathrm{ng} / \mu \mathrm{l}$ dissolved in $17 \mu \mathrm{l}$ of hybridization buffer) and the slide were separately denatured during $10 \mathrm{~min}$ at $85^{\circ} \mathrm{C}$. Then we deposited the probes onto the slide, which was then placed for 24 hours at $37^{\circ} \mathrm{C}$ in a humidified chamber. After two rinses in $2 \mathrm{XSSC}$ at $42^{\circ} \mathrm{C}$, samples were post-fixed in 2\% PFA for $15 \mathrm{~min}$.

The 3D-FISH hybridization with the probes for ribosomal genes (18S and $28 \mathrm{~S}$ together) was performed as follows: isolated oocytes were fixed with $4 \%$ paraformaldehyde (PFA) for $10 \mathrm{~min}$ and treated according to Koehler and coworkers (2009) with slight modifications. Briefly, the zona pellucida was removed in $0.1 \mathrm{~N} \mathrm{HCl}$ under a stereomicroscope. Then the oocytes were permeabilized 1 hour in $0.5 \%$ Triton $\mathrm{X}-100$ and incubated in $0.1 \mathrm{~N} \mathrm{HCl}$ for $1 \mathrm{~min}$. Finally, the oocytes were transferred into $50 \%$ formamide/2XSSC, at $27^{\circ} \mathrm{C}$ for 72 hours in the hybridization oven. After this incubation; the oocytes were washed twice in $0.05 \%$ Triton $\mathrm{X}-100$ for $5 \mathrm{~min}$ and incubated again $1 \mathrm{~h}$ in Triton X-100 (0.5\%) with RNase $\left(200 \mu \mathrm{g} / \mathrm{ml}\right.$, Sigma) at $27^{\circ} \mathrm{C}$, in $\mathrm{HCl}$ for $1 \mathrm{~min}$ and transferred into $50 \%$ formamide/2XSSC, at $27^{\circ} \mathrm{C}$ for 72 hours in the hybridization oven. The oocytes were transferred in $20 \mu \mathrm{l}$ of the hybridization mixture containing $9 \mu \mathrm{l}$ of $18 \mathrm{~S}$ and $9 \mu \mathrm{l}$ of 28S rDNA probes (at $20 \mathrm{ng} / \mu \mathrm{l}$ ) as well as $2 \mu \mathrm{l}$ of major satellite probes (at $100 \mathrm{ng} /$ $\mu \mathrm{l})$. Following 3 hours incubation at $37^{\circ} \mathrm{C}$, denaturation was performed at $85^{\circ} \mathrm{C}$ for 10 minutes and the oocytes were then placed in the hybridization oven for 72 hours at $37^{\circ} \mathrm{C}$. After several washes in 2XSSC, $50 \% \mathrm{~F} / 2 \mathrm{XSSC}$ and 0.1 XSSC for $10 \mathrm{~min}$ at RT to remove un-hybridized probes, immunodetection of the hybridized probes was performed as above: the oocytes were first incubated overnight at $+4^{\circ} \mathrm{C}$ with the sheep anti-Dig primary antibody (Roche, 1:200 in 4\% BSA) followed by a second incubation with an anti-sheep secondary antibody at room temperature for 1 hour (Jackson Immuno research, 1:200).

\section{Observation with high resolution microscopy}

After immuno-fluorescent staining or FISH-3D, DNA counterstaining was performed with YOPRO (Molecular probes, $1 \mu \mathrm{M}$ ) or propidium iodide (Sigma, $1 \mu \mathrm{g} / \mathrm{ml}$ ). Oocytes were then post-fixed with 2\% PFA for $15 \mathrm{~min}$ at RT, washed and mounted on slides with an antifading agent (Citifluor) under coverslips.

3D-preserved oocytes were observed with a Carl Zeiss AxioObserver Zl fluorescence microscope equipped with a Zeiss LSM 510 confocal laser scanning microscope (MIMA2 Platform, INRA). On the confocal system, oocytes were visualized with an oil-immersion objective (Plan Apochromatic 63X NA 1.4) and imaging was performed with lasers at 488-, 535- and 633$\mathrm{nm}$ wavelengths. Entire oocytes were scanned with a distance of $0.37 \mu \mathrm{m}$ between light optical sections.

\section{Statistical analysis}

Statistical analysis and boxplot representations were performed with the R statistical software (http://www.r-project.org). The data were compared using a Kruskall-Wallis rank sum test.

\section{Competing interests}

The authors have nothing to disclose; no competing financial interests exist. 


\section{Acknowledgements}

We thank Josette Catalan and Benoite Cazaux for their help with rDNA FISH probes. We are grateful to Tiphaine Aguirre-Lavin and Claire Bouleisteix for their support and assistance. We also acknowledge the platform MIMA2 (Microscopie et Imagerie des Microorganismes, Animaux et Elements), especially Pierre Adenot, for confocal microscopy and UEIERP for animal care (Unité Expérimentale d'Infectiologie Expérimentale des Rongeurs et Poissons). The present work was supported by INRA « Jeune Equipe » funding.

\section{References}

ANDREU-VIEYRA, C.V., CHEN, R., AGNO, J.E., GLASER, S., ANASTASSIADIS, K., STEWART, A.F. and MATZUK, M.M. (2010). MLL2 is required in oocytes for bulk histone 3 lysine 4 trimethylation and transcriptional silencing. PLOS Biol 8.

BANNISTER, A.J., ZEGERMAN, P., PARTRIDGE, J.F., MISKA, E.A., THOMAS, J.O., ALLSHIRE, R.C. and KOUZARIDES, T. (2001). Selective recognition of methylated lysine 9 on histone H3 by the HP1 chromo domain. Nature 410: 120-124.

BERNSTEIN, B.E., MIKKELSEN, T.S., XIE, X., KAMAL, M., HUEBERT, D.J., CUFF, J., FRY, B., MEISSNER, A., WERNIG, M., PLATH, K. et al., (2006). A bivalent chromatin structure marks key developmental genes in embryonic stem cells. Cell 125: 315-326.

BOUNIOL-BALY, C., HAMRAOUI, L., GUIBERT, J., BEAUJEAN, N., SZOLLOSI, M.S. and DEBEY, P. (1999). Differential transcriptional activity associated with chromatin configuration in fully grown mouse germinal vesicle oocytes. Biol Reprod 60: 580-587.

CHANG, C.C., MA, Y., JACOBS, S., TIAN, X.C., YANG, X. and RASMUSSEN, T.P. (2005). A maternal store of macroH2A is removed from pronuclei prior to onset of somatic macroH2A expression in preimplantation embryos. Dev Bio/278: 367-380.

CHOO, K.H. (1997). Centromere DNA dynamics: latent centromeres and neocentromere formation. Am J Hum Genet 61: 1225-1233.

CHOO, K.H. (2000). Centromerization. Trends Cell Biol 10: 182-8.

CHRISTIANS, E., BOIANI, M., GARAGNA, S., DESSY, C., REDI, C.A., RENARD, J.P. and ZUCCOTTI, M. (1999). Gene expression and chromatin organization during mouse oocyte growth. Dev Biol 207: 76-85.

DE LA FUENTE, R. (2006). Chromatin modifications in the germinal vesicle (GV) of mammalian oocytes. Dev Biol 292: 1-12.

DE LA FUENTE, R. and EPPIG, J.J. (2001). Transcriptional activity of the mouse oocyte genome: companion granulosa cells modulate transcription and chromatin remodeling. Dev Biol 229: 224-236.

DE LA FUENTE, R., VIVEIROS, M.M., WIGGLESWORTH, K. and EPPIG, J.J. (2004). ATRX, a member of the SNF2 family of helicase/ATPases, is required for chromosome alignment and meiotic spindle organization in metaphase II stage mouse oocytes. Dev Biol 272: 1-14.

DEBEY, P., SZOLLOSI, M.S., SZOLLOSI, D., VAUTIER, D., GIROUSSE, A. and BESOMBES, D. (1993). Competent mouse oocytes isolated from antral follicles exhibit different chromatin organization and follow different maturation dynamics. Mol Reprod Dev 36: 59-74.

FRANCASTEL, C., SCHUBELER, D., MARTIN, D.I. and GROUDINE, M. (2000). Nuclear compartmentalization and gene activity. Nat Rev Mol Cell Biol1: 137-143.

FRANCASTEL, C., WALTERS, M.C., GROUDINE, M. and MARTIN, D.I. (1999). A functional enhancer suppresses silencing of a transgene and prevents its localization close to centrometric heterochromatin. Cell 99: 259-269.

GARAGNA, S., MERICO, V., SEBASTIANO, V., MONTI, M., ORLANDINI, G., GATTI, R., SCANDROGLIO, R., REDI, C.A. and ZUCCOTTI, M. (2004). Three-dimensional localization and dynamics of centromeres in mouse oocytes during folliculogenesis. J Mol Histol 35: 631-638.

GILBERT, N., BOYLE, S., FIEGLER, H., WOODFINE, K., CARTER, N.P. and BICKMORE, W.A. (2004). Chromatin architecture of the human genome: gene-rich domains are enriched in open chromatin fibers. Cell 118: 555-566.

HASSOUNA, N., MICHOT, B., BACHELLERIE, J.P. (1984). The complete nucleotide sequence of mouse 28S rRNAgene. Implications for the process of size increase of the large subunitrRNA in higher eukaryotes. Nucleic Acids Research12:3563-3583.

INOUE, A., NAKAJIMA, R., NAGATA, M. and AOKI, F. (2008). Contribution of the oocyte nucleus and cytoplasm to the determination of meiotic and developmental competence in mice. Hum Reprod 23: 1377-1384.

KAGEYAMA, S., LIU, H., KANEKO, N., OOGA, M., NAGATA, M. and AOKI, F. (2007), Alterations in epigenetic modifications during oocyte growth in mice. Reproduction 133: 85-94.

KAPLAN, G., ABREU, S.L. and BACHVAROVA, R. (1982). rRNA accumulation and protein synthetic patterns in growing mouse oocytes. J Exp Zool 220: 361-370.

KIM, J.M., LIU, H., TAZAKI, M., NAGATA, M. and AOKI, F. (2003). Changes in histone acetylation during mouse oocyte meiosis. J Cell Biol 162: 37-46.

KOEHLER, D., ZAKHARTCHENKO, V., FROENICKE, L., STONE, G., STANYON, R., WOLF, E., CREMER, T. and BRERO, A. (2009). Changes of higher order chromatin arrangements during major genome activation in bovine preimplantation embryos. Exp Cell Res 315: 2053-2063.

KOPECNY, V., LANDA, V. and PAVLOK, A. (1995). Localization of nucleic acids in the nucleoli of oocytes and early embryos of mouse and hamster: an autoradiographic study. Mol Reprod Dev 41: 449-458.

KOUZARIDES, T. (2007). Chromatin modifications and their function. Cell128:693-705.

LACHNER, M., O'CARROLL, D., REA, S., MECHTLER, K. and JENUWEIN, T. (2001). Methylation of histone $\mathrm{H} 3$ lysine 9 creates a binding site for HP1 proteins. Nature 410: 116-120.

LIU, H. and AOKI, F. (2002). Transcriptional activity associated with meiotic competence in fully grown mouse GV oocytes. Zygote 10: 327-332.

LIU, H., KIM, J.M. and AOKI, F. (2004). Regulation of histone H3 lysine 9 methylation in oocytes and early pre-implantation embryos. Development 131: 2269-2280.

LIU, Y.J., NAKAMURA, T. and NAKANO, T. (2012). Essential role of DPPA3 for chromatin condensation in mouse oocytogenesis. Biol Reprod 86: 40, 1-8.

LONGO, F., GARAGNA, S., MERICO, V., ORLANDINI, G., GATTI, R., SCANDROGLIO, R., REDI, C.A. and ZUCCOTTI, M. (2003). Nuclear localization of NORs and centromeres in mouse oocytes during folliculogenesis. Mol Reprod Dev 66: 279-290.

MAALOUF, W.E., LIU, Z., BROCHARD, V., RENARD, J.P., DEBEY, P., BEAUJEAN, N. and ZINK, D. (2009). Trichostatin A treatment of cloned mouse embryos improves constitutive heterochromatin remodeling as well as developmental potential to term. BMC Dev Biol 9: 11

MATTSON, B.A. and ALBERTINI, D.F. (1990). Oogenesis: chromatin and microtubule dynamics during meiotic prophase. Mol Reprod Dev 25: 374-383.

MEGLICKI, M., ZIENTARSKI, M. and BORSUK, E. (2008). Constitutive heterochromatin during mouse oogenesis: the pattern of histone $\mathrm{H} 3$ modifications and localization of HP1alpha and HP1beta proteins. Mol Reprod Dev 75: 414-428.

MIYARA, F., MIGNE, C., DUMONT-HASSAN, M., LE MEUR, A., COHEN-BACRIE, P., AUBRIOT, F.X., GLISSANT, A., NATHAN, C., DOUARD, S., STANOVICI, A. et al., (2003). Chromatin configuration and transcriptional control in human and mouse oocytes. Mol Reprod Dev 64: 458-470.

PARFENOV, V., POTCHUKALINA, G., DUDINA, L., KOSTYUCHEK, D. and GRUZOVA, M. (1989). Human antral follicles: oocyte nucleus and the karyosphere formation (electron microscopic and autoradiographic data). Gamete Res 22: 219-231.

PETERS, A.H., KUBICEK, S., MECHTLER, K., O'SULLIVAN, R.J., DERIJCK, A.A., PEREZ-BURGOS, L., KOHLMAIER, A., OPRAVIL, S., TACHIBANA, M., SHINKAI, Y. et al., (2003). Partitioning and plasticity of repressive histone methylation states in mammalian chromatin. Mol Cell 12: 1577-1589.

RAYNAL, F., MICHOT, B., BACHELLERIE, J.P. (1984) Complete nucleotide sequence of mouse $18 \mathrm{~S}$ rRNA gene: comparison with other available homologs. FEBS Letters 167:263-268.

ROMANOVA, L., KOROBOVA, F., NONIASHVILLI, E., DYBAN, A. and ZATSEPINA, O. (2006). High resolution mapping of ribosomal DNA in early mouse embryos by fluorescence in situ hybridization. Biol Reprod 74: 807-815.

SARMENTO, O.F., DIGILIO, L.C., WANG, Y., PERLIN, J., HERR, J.C., ALLIS, C.D. and COONROD, S.A. (2004). Dynamic alterations of specific histone modifications during early murine development. J Cell Sci 117: 4449-4459.

SCHNEIDER, R. and GROSSCHEDL, R. (2007). Dynamics and interplay of nuclear architecture, genome organization, and gene expression. Genes Dev21:3027-3043.

SPINACI, M., SEREN, E. and MATTIOLI, M. (2004). Maternal chromatin remodeling during maturation and after fertilization in mouse oocytes. Mol Reprod Dev 69: 215-221.

TESSADORI, F., CHUPEAU, M.C., CHUPEAU, Y., KNIP, M., GERMANN, S., VAN DRIEL, R., FRANSZ, P. and GAUDIN, V. (2007). Large-scale dissociation and sequential reassembly of pericentric heterochromatin in dedifferentiated Arabi- 
dopsis cells. J Cell Sci 120: 1200-1208.

TROJER, P. and REINBERG, D. (2007). Facultative heterochromatin: is there a distinctive molecular signature? Mol Cell 28: 1-13.

WANG, Q., AI, J.S., IDOWU OLA, S., GU, L., ZHANG, Y.Z., CHEN, D.Y. and SUN, Q.Y. (2008). The spatial relationship between heterochromatin protein 1 alpha and histone modifications during mouse oocyte meiosis. Cell Cycle 7: 513-520.

ZATSEPINA, O.V., BOUNIOL-BALY, C., AMIRAND, C. and DEBEY, P. (2000). Functional and molecular reorganization of the nucleolar apparatus in maturing mouse oocytes. Dev Biol 223: 354-370.

ZHOU, V.W., GOREN, A. and BERNSTEIN, B.E. (2011). Charting histone modifications and the functional organization of mammalian genomes. Nat Rev Genet 12: 7-18.

ZINK, D., FISCHER, A.H. and NICKERSON, J.A. (2004). Nuclear structure in cancer cells. Nat Rev Cancer 4: 677-687.

ZUCCOTTI, M., GARAGNA, S., MERICO, V., MONTI, M. and ALBERTO REDI, C. (2005). Chromatin organisation and nuclear architecture in growing mouse oocytes. Mol Cell Endocrinol 234: 11-17.

ZUCCOTTI, M., GIORGI ROSSI, P., FIORILLO, E., GARAGNA, S., FORABOSCO, A and REDI, C.A. (1998). Timing of gene expression and oolemma localization of mouse alpha6 and beta1 integrin subunits during oogenesis. Dev Biol 200: 27-34

ZUCCOTTI, M., MERICO, V., SACCHI, L., BELLONE, M., BRINK, T.C., BELLAZZI, R., STEFANELLI, M., REDI, C.A., GARAGNA, S. and ADJAYE, J. (2008). Maternal Oct-4 is a potential key regulator of the developmental competence of mouse oocytes. BMC Dev Biol 8: 97.

ZUCCOTTI, M., PICCINELLI, A., GIORGI ROSSI, P., GARAGNA, S. and REDI, C.A. (1995). Chromatin organization during mouse oocyte growth. Mol Reprod Dev 41: 479-485.

ZUCCOTTI, M., PONCE, R.H., BOIANI, M., GUIZZARDI, S., GOVONI, P., SCANDROGLIO, R., GARAGNA, S. and REDI, C.A. (2002). The analysis of chromatin organisation allows selection of mouse antral oocytes competent for development to blastocyst. Zygote 10: 73-78. 


\section{Further Related Reading, published previously in the Int. J. Dev. Biol.}

Impaired meiotic competence in putative primordial germ cells produced from mouse embryonic stem cells Marianna Tedesco, Donatella Farini and Massimo De Felici

Int. J. Dev. Biol. (2011) 55: 215-222

Generation of germ-line chimera zebrafish using primordial germ cells isolated from cultured blastomeres and cryopreserved embryoids

Yutaka Kawakami, Rie Goto-Kazeto, Taiju Saito, Takafumi Fujimoto, Shogo Higaki, Yoshiyuki Takahashi, Katsutoshi Arai and Etsuro Yamaha

Int. J. Dev. Biol. (2010) 54: 1493-1501

In vitro germ cell differentiation during sex differentiation in a teleost fish Tohru Kobayashi

Int. J. Dev. Biol. (2010) 54: 105-111

Differentiation of mouse primordial germ cells into female or male germ cells N Nakatsuji and S Chuma

Int. J. Dev. Biol. (2001) 45: 541-548

The meiotic specific synaptonemal complex protein SCP3 is expressed by female and male primordial germ cells of the mouse embryo

A D Di Carlo, G Travia and M De Felici

Int. J. Dev. Biol. (2000) 44: 241-244

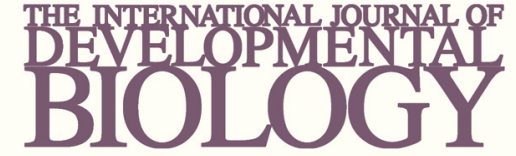

Volume 54 Nos. $6 / 7$
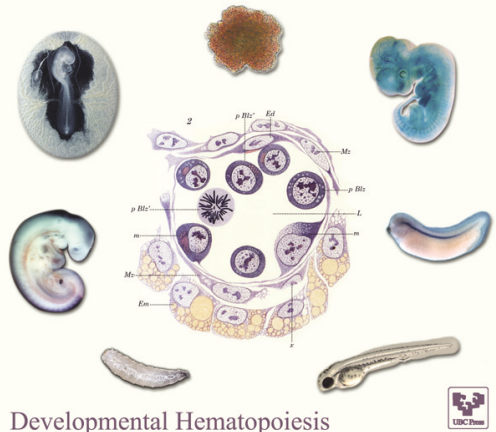

5 yr ISI Impact Factor $(2011)=2.959$
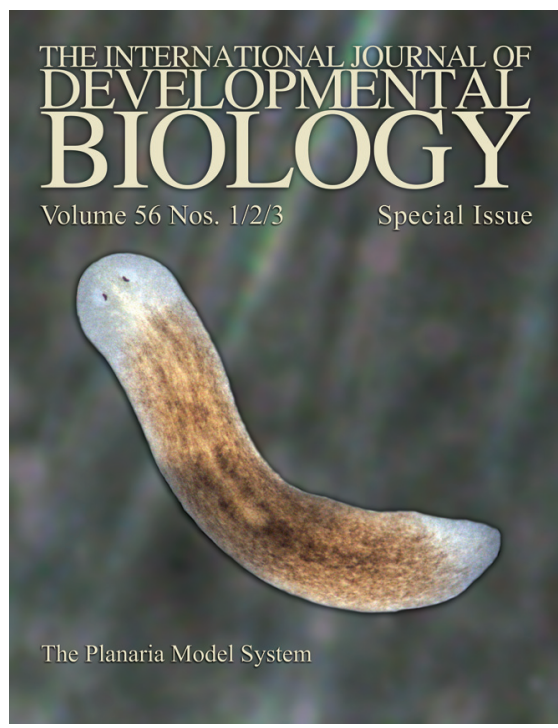
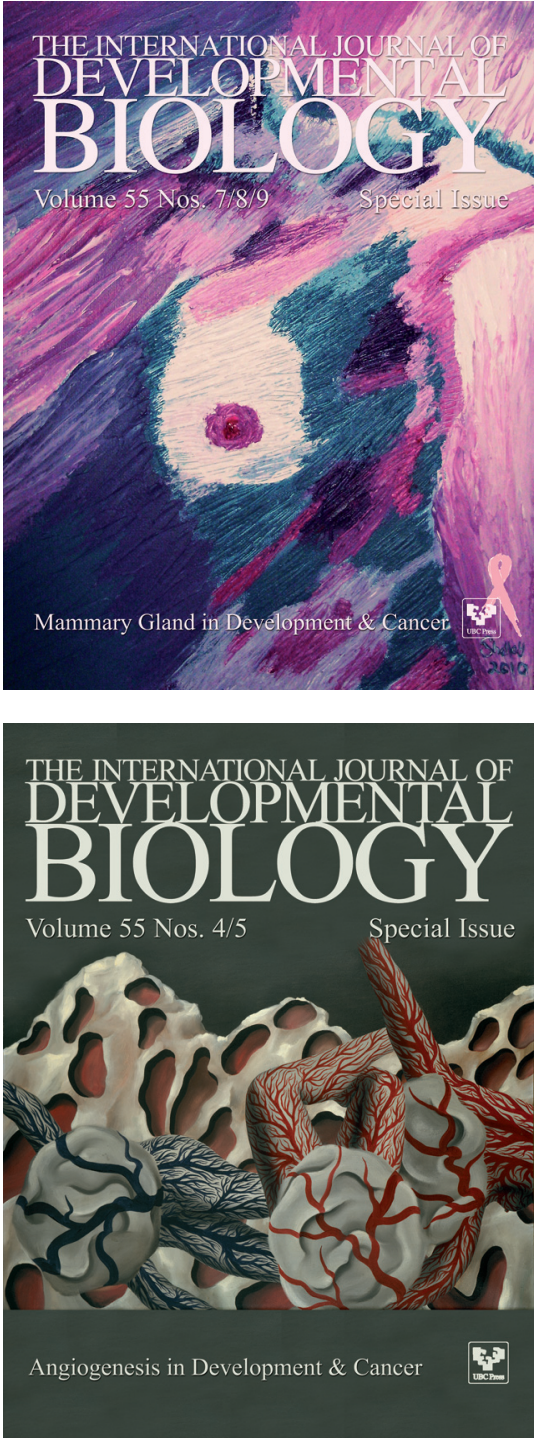